\title{
Sensitivity of Surface Temperature to Oceanic Forcing via $q$-Flux Green's Function Experiments. Part II: Feedback Decomposition and Polar Amplification
}

\author{
FUKAI LIU \\ Physical Oceanography Laboratory, Collaborative Innovation Center of Marine Science and Technology, \\ Ocean University of China, and Qingdao National Laboratory for Marine Science and Technology, Qingdao, China \\ JiAN LU AND OLUWAYEMi A. GARUBA \\ Atmospheric Sciences and Global Change Division, Pacific Northwest National Laboratory, Richland, Washington \\ YI HUANG \\ Department of Atmospheric and Oceanic Sciences, McGill University, Montreal, Quebec, Canada \\ L. RUBy LEUNG AND BRYCE E. HARROP \\ Atmospheric Sciences and Global Change Division, Pacific Northwest National Laboratory, Richland, Washington

\section{YIYONG LUO} \\ Physical Oceanography Laboratory, Collaborative Innovation Center of Marine Science and Technology, \\ Ocean University of China, and Qingdao National Laboratory for Marine Science and Technology, Qingdao, China
}

(Manuscript received 23 January 2018, in final form 9 May 2018)

\section{ABSTRACT}

\begin{abstract}
A large set of Green's function-type experiments is performed with $q$-flux forcings mimicking the effects of the ocean heat uptake (OHU) to examine the global surface air temperature (SAT) sensitivities to the location of the forcing. The result of the experiments confirms the earlier notion derived from experiments with different model complexities that the global mean SAT is far more sensitive to the oceanic forcing from high latitudes than the tropics. Remarkably, no matter in which latitude the $q$-flux forcings are placed, the SAT response is always characterized by a feature of polar amplification, implicating that it is intrinsic to our climate system. Considerable zonal asymmetry is also present in the efficacy of the tropical OHU, with the tropical eastern Pacific being much more efficient than the Indian Ocean and tropical Atlantic in driving global SAT warming by exciting the leading neutral mode of the SAT that projects strongly onto global mean warming. Using a radiative kernel, feedback analysis is also conducted to unravel the underlying processes responsible for the spatial heterogeneity in the global OHU efficacy, the polar amplification structures, and the tropical altruism of sharing the warmth with remote latitudes. Warming "altruism" for a $q$ flux at a given latitude is also investigated in terms of the ratio of the induced remote latitudes versus the directly forced local warming. It is found that the tropics are much more altruistic than higher latitudes because of the high-energy transport efficiency of the Hadley circulation.
\end{abstract}

\section{Introduction}

The ocean is an important regulator of the global climate. Owing to its large heat capacity and circulation, the ocean has large influences on both the mean state and variability of the climate, as well as the climate response to external forcings. Unlike the atmosphere, which

Corresponding author: Jian Lu, jian.lu@pnnl.gov has a short memory, with long time scales the ocean is the pacemaker for the slow evolution of regional (e.g., Read and Gould 1992; Delworth et al. 1993; Chang et al. 2008) and global climate (e.g., Marshall et al. 2015; Xie and Vallis 2012; Winton et al. 2013; Garuba and Klinger 2016), both through direct heating/cooling of the atmosphere and cryosphere and indirectly through induced radiative feedbacks (Winton et al. 2010; Armour et al. 2013; Rose et al. 2014; Rose and Rayborn 2016; 
Gregory and Andrews 2016). In particular, the transient climate sensitivity, measured by the inverse of the rate of the global mean surface temperature $(\Delta T)$ increases with respect to the top of the atmosphere (TOA) radiation imbalance in response to an instantaneous doubling of $\mathrm{CO}_{2}$ forcing [i.e., $\lambda^{*}=(R-H) / \Delta T$, where $R$ is the instantaneous radiative forcing at the TOA due to the increase of $\mathrm{CO}_{2}$ concentration and $H$ is the ocean heat uptake (OHU); both $H$ and $\Delta T$ are functions of time], has been shown to be smaller than its equilibrium counterpart $\left(\lambda_{\mathrm{CO} 2}=R / \Delta T_{e}\right.$, where $\Delta T_{e}$ is the equilibrium global mean temperature response; Senior and Mitchell 2000; Williams et al. 2008; Winton et al. 2013; Armour et al. 2013), and this discrepancy has been attributed to the intrinsically large efficacy of the ocean heat uptake in the high-latitude oceans in hindering global warming (Geoffroy et al. 2013; Rose et al. 2014; Rugenstein et al. 2016). The concept of OHU efficacy was first adopted by Winton et al. (2010) by treating the OHU as a forcing agent to the climate (Hansen et al. 1997). During the transient adjustment of the climate to $\mathrm{CO}_{2}$ forcing, most of the energy goes into the ocean because of its large heat inertia, therefore the ocean heat uptake can be thought of as a forcing working to delay the $\mathrm{CO}_{2}$-induced warming at an efficiency of $1 / \lambda_{\mathrm{OHU}}=\Delta T / H$. The efficacy of the OHU can be defined as the ratio of $1 / \lambda_{\mathrm{OHU}}$ to the global warming sensitivity to the $\mathrm{CO}_{2}$ forcing $\left(1 / \lambda_{\mathrm{CO} 2}\right)$, that is, $\varepsilon=\lambda_{\mathrm{CO} 2} / \lambda_{\mathrm{OHU}}$, where $\lambda_{\mathrm{CO} 2}$ and $\lambda_{\mathrm{OHU}}\left(\mathrm{Wm}^{-2} \mathrm{~K}^{-1}\right)$ are the climate feedback parameters in response to $\mathrm{CO}_{2}$ forcing and OHU, respectively (Rose and Rayborn 2016). The $\lambda_{\mathrm{CO} 2}$ estimated from AGCM coupled to a slab ocean turned out to be $0.75 \mathrm{~W} \mathrm{~m}^{-2} \mathrm{~K}^{-1}$ for National Center for Atmospheric Research (NCAR) CAM5 (Garuba et al. 2018). For an OHU efficacy $>1$, less than $0.75 \mathrm{~W} \mathrm{~m}^{-2}$ of $\mathrm{OHU}$ is needed to alleviate $1 \mathrm{~K}$ global warming induced by $\mathrm{CO}_{2}$ radiative forcing in this model. Moreover, Rose et al. (2014) identified the efficacy of the mid- to high-latitude OHU to be 3-4 times as large as that of the tropical OHU in an aquaplanet AGCM, and attributed this contrast in efficacy to the distinct positive shortwave cloud radiative (Cld) feedback (see also Rugenstein et al. 2016).

These findings prompt us to investigate the climate warming efficacies and the related feedback processes for all ocean locations in a realistic climate model. We achieve this through a large set of slab ocean model experiments with NCAR CAM5 (Neale et al. 2012) forced by $q$-flux patches tiling over all the ice-free ocean of the globe, one at a time. The $q$-flux anomaly patches here are used to represent the OHU through the bottom of the slab mixed layer, to the extent that the OHU in the fully coupled climate system is assumed to take place at a much slower time scale than the intrinsic atmospheric time scales, and the atmosphere is assumed to be in equilibrium with the
OHU. We refer to these experiments as the $q$-flux Green's function experiments (Barsugli and Sardeshmukh 2002; Barsugli et al. 2006), as the response to an individual $q$-flux patch asymptotes to the Green's function solution under the limit of the forcing approaching a Dirac delta function. In Liu et al. (2018, hereafter Part I), we have successfully constructed the linear response function $(\mathbf{L})$ of the sea surface temperature (SST, $\delta \mathbf{T}$ ) to ocean $q$ flux ( $\delta \mathbf{f})$ using the Green's function experiments, and identified the first most excitable SST mode (neutral mode) as the interdecadal Pacific oscillation (IPO) pattern and the second most excitable mode as the pattern of interhemispheric SST contrast. The neutral modes and their corresponding optimal forcing patterns are paired up with each other as the leading right and left singular vectors of the linear response function that links the equilibrium SST response to the ocean $q$ flux via $\mathbf{L} \delta \mathbf{T}=-\delta \mathbf{f}$. Therefore, the sign of the loading of a left singular vector at a given location can help predict the sign of the response of the corresponding right singular vector to a forcing from that location. $\mathbf{L}$ encompasses all the linear relationships between SST and $q$-flux forcing, and accurate representation of $\mathbf{L}$ of an AGCM can translate between $q$-flux forcing and SST response without running actual numerical experiments.

In Part II, here, we make use of the Green's function experiments to first verify that the conclusions of Rose et al. (2014) from aquaplanet simulations also hold in a comprehensive model: High-latitude OHU efficacy is greater than unity and a unit high-latitude flux drives a global surface air temperature (SAT) anomaly 3 to 4 times as large as that driven by a unit low-latitude flux. We will also demonstrate that, indeed, the equatorial regions are warmed more effectively by polar forcing than the local forcing in our sensitivity experiments, as found in the idealized aquaplanet models (e.g., Kang and Xie 2014; Kang et al. 2017). The two-dimensional array of the $q$ flux in the Green's function experiments also allows us to probe into the zonal asymmetry and the interhemispheric asymmetry in the radiative feedbacks to the OHU, as well as addressing the curious question of how local atmospheric heating propagates to influence remote climate and gets amplified by radiative feedbacks. In particular, we will examine the role of the leading neutral modes of the slab-coupled climate system in organizing the feedback processes that constitute the relatively weak SAT warming efficacy of heat fluxes from the tropical Indian and Atlantic Oceans compared to that from the eastern Pacific Ocean. In addition, we utilize a radiative kernel to diagnose the specific feedback processes, through which we gain insights into how the remote response to a given $q$ flux gets suppressed or amplified, a question with important bearing on the intrinsic propensity of our climate system to amplify the polar response. 
The rest of the paper is organized as follows: Section 2 briefly describes the Green's function experiments and introduces a method to attribute SAT response to different radiative kernel feedbacks. Section 3 addresses the zonal-mean SAT sensitivity to $q$-flux perturbation at different latitudes. Section 4 examines the zonal asymmetric effectiveness of tropical oceans in driving global SAT changes. A perspective of neutral vector is introduced in section 5 for understanding the sensitivity of the global SAT response. The paper concludes with a summary of the results.

\section{Methods}

\section{a. Model and experiments}

The model used is the slab version of Community Earth System Model, version 1.1 (CESM1.1-SOM), in which the atmosphere (Community Atmospheric Model, version 5; CAM5), land (Community Land Model, version 4; CLM4), and sea ice (Community Ice Code, CICE) components are coupled to a motionless slab of ocean representing its mixed layer. CAM5 has been modified substantially with a range of significant enhancements and improvements in the representation of physical processes (Neale et al. 2012), including the updated cloud microphysics scheme to capture the cloud-aerosol indirect radiative effects (Zhao et al. 2012). The horizontal resolution of CAM5 and CLM4 is $2.5^{\circ}$ longitude $\times 1.9^{\circ}$ latitude. The horizontal resolution of the CICE and SOM is at a nominal $1^{\circ}$, telescoped meridionally to $\sim 0.3^{\circ}$ at the equator. In this model, SST is prognostic and determined by the thermal coupling between the slab ocean and atmosphere.

The control simulation (CTRL) is a 900-yr CESM1.1SOM from NCAR, forced with preindustrial carbon dioxide levels and solar insolation. Both the mixed layer depth and the $q$ flux used in CTRL are diagnosed from a fully coupled CESM1.1 control simulation; the former varies in space but is constant in time, while the latter has a repeating seasonal cycle. Branching out from 1 January of a year arbitrarily chosen from the equilibrated CTRL run, we perform 97 pairs of "warm patch" and "cold patch" simulations, in which the $q$-flux patch is added to or subtracted from the climatological $q$ flux. The locations of the $97 q$-flux patches are illustrated as contours in Fig. 1 of Part I. For each location, the $q$-flux patch is specified to be a localized hump following Barsugli and Sardeshmukh (2002):

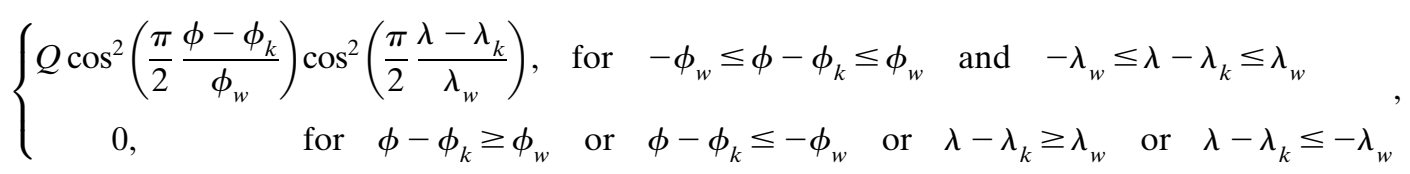

where $Q$ is the peak value of the $q$-flux patch and set to be $\pm 12 \mathrm{~W} \mathrm{~m}^{-2}$ at the center of the rectangular patch $\left(\phi_{k}\right.$, $\left.\lambda_{k}\right)$. The half-widths of the rectangular patch in zonal $\left(\lambda_{w}\right)$ and meridional $\left(\phi_{w}\right)$ directions are $30^{\circ}$ and $12^{\circ}$, respectively, which also are the zonal and meridional distances between the adjacent patches. The summation of the 97 patches leads to a uniform $12 \mathrm{~W} \mathrm{~m}^{-2}$ perturbation covering the entire global ocean, except near the coast and the edge of sea ice. Each of the patch experiments is integrated for 40 years to reach equilibrium and only the output of the last 20 years is analyzed, with the prior years discarded as spinup. Only the linear component of the response is examined, which, for an arbitrary variable of interest $T$, can be estimated to be $T_{l}=\left(T_{+}-T_{-}\right) / 2$, with the subscript $+(-)$ denoting the response in the $+12(-12) \mathrm{W} \mathrm{m}^{-2}$ simulation. Further details of these experiments can be found in Part I.

\section{b. Radiative kernel and attribution of SAT sensitivity to radiative feedbacks}

To diagnose the radiative feedbacks to $q$-flux forcing, we employ the radiative kernels developed by Huang et al. (2017). These kernels are calculated using the Rapid Radiative Transfer Model (RRTM) of Mlawer et al. (1997) based on 6-hourly atmospheric profiles from the ERA-Interim reanalysis dataset (Dee et al. 2011). For each profile, both clear- and all-sky radiative fluxes are computed. Monthly mean kernels of each calendar month at every grid box $\left(2.5^{\circ}\right.$ by $2.5^{\circ}$ at 19 levels $)$ are then obtained by averaging the 6-hourly sensitivities of that month. The CAM5 output is then linearly interpolated onto this grid for computing the radiative fluxes. Although the kernels are calculated from the reanalysis, when applied to CAM5 they can reproduce accurately the GCM-simulated radiation anomalies (Huang et al. 2017), justifying the practice of applying these kernels to the feedbacks in CAM5. Monthly all-sky kernels are utilized for the purpose of the present study.

To explain the SAT response sensitivity to the $q$-flux forcing from different latitudes, we construct an attribution framework based on the energy balance among surface heat flux $\left(F_{s}\right)$, the sum of the TOA radiation components $\left(R_{i}\right)$, and the divergence of the vertically integrated atmospheric heat transport (AHT, $F$ ), that is, 


$$
\nabla \cdot F^{\prime}=\sum R_{i}^{\prime}+F_{S}^{\prime}
$$

where prime indicates departure from the control. Since the slab is close to equilibrium in all experiments, $F_{S}^{\prime} \approx Q^{\prime}$ in the $q$-flux patch and $F_{S}^{\prime} \approx 0$ outside of the patch. The TOA radiative fluxes $\left(R_{i}^{\prime}\right)$ comprise the lapse rate (LR), water vapor (WV), cloud, albedo (Alb), and vertically integrated Planck radiative effects; the last of these is expressed as

$$
\left(\frac{\partial R}{\partial T_{s}}+\int \frac{\partial R}{\partial T} d p\right) T_{s}^{\prime}
$$

where $\partial R / \partial T_{s}$ and $\partial R / \partial T$ are the surface temperature kernel and air temperature kernel, respectively, calculated for the full sky using ERA-Interim data (Dee et al. 2011). The operator $\left[\left(\partial R / \partial T_{s}\right)+\int(\partial R / \partial T) d p\right]$, denoted as $k_{P}$, will be referred to as the column Planck feedback parameter. Its inverse $k_{P}^{-1}$ measures the vertically homogeneous temperature change needed to damp a given radiative forcing through the Planck effect. Equation (2) hence can be written in the form of the maintenance of $T_{s}^{\prime}$ by the different radiative feedbacks (barring the Planck) and the AHT through the column Planck feedback:

$$
T_{s}^{\prime}=-k_{p}^{-1}\left(\sum R_{i}^{\prime}+F_{s}^{\prime}-\nabla \cdot F^{\prime}\right),
$$

where the subscript $i$ is now for the radiative feedbacks other than the Planck feedback. Equation (4) constitutes an attribution framework for interpreting the spatial structure of the SAT response to a given $q$-flux forcing in terms of different radiative feedbacks and the convergence of AHT. Similar framework has been developed for interpreting the spatial patterns of climate feedback and temperature response to $\mathrm{CO}_{2}$ forcing ( $\mathrm{Lu}$ and $\mathrm{Cai}$ 2009; Crook et al. 2011). In Figs. $1 \mathrm{~b}$ and 2, to be discussed in more detail, we verify that $T_{s}^{\prime}$ at each latitude can be additively decomposed into the anomalies due to 1) water vapor feedback, 2) albedo feedback, 3) lapse rate feedback, 4) cloud feedback, 5) convergence of AHT, and 6) the local $q$ flux $\left(F_{s}^{\prime}=Q^{\prime}\right)$.

For the change in TOA radiative effects, the noncloud effects are computed directly using the kernels, and the cloud radiative feedback is obtained by subtracting the sum of noncloud feedback from the GCM-simulated overall radiation change: $\Delta R_{C}=\Delta R_{\mathrm{GCM}}-\sum K_{X} \Delta X$, where subscript $C$ refers to cloud and $X$ refers to Planck, lapse rate, water vapor, and surface albedo. Both the longwave (LW) and shortwave (SW) components of the cloud feedback are diagnosed this way (Fig. 4). We have recomputed the cloud radiative feedback following the approach of Soden et al. (2008) to correct the cloud masking effect; the result is almost indistinguishable from what is shown in Figs. 1 and 2f.

\section{Zonal-mean SAT sensitivity}

\section{a. SAT sensitivity and ocean q-flux efficacy}

The SAT sensitivity here is defined as the global-mean SAT equilibrium response normalized by the area integration of the $q$-flux perturbation over each patch, representing the efficiency of the $q$-flux forcing of a given location in driving the global-mean SAT response. The geographical distribution of the global-mean SAT sensitivity is shown as color shading in Fig. 1a; the sensitivity map is smoothed with a gap-filling algorithm based on discrete cosine transforms (Garcia 2010). The sensitivity map features large sensitivity in the Southern Ocean, the North Pacific, and North Atlantic Oceans and weak sensitivity in the tropical oceans, especially the western Indian Ocean and tropical eastern Atlantic. The much greater sensitivity to higher-latitude forcing corroborates earlier results from idealized aquaplanet experiments (Forster et al. 2000; Joshi et al. 2003; Rose et al. 2014; Kang and Xie 2014). Winton et al. (2010) introduced an OHU "efficacy" concept to account for the sensitivity of global surface temperature to $\mathrm{OHU}$ relative to $\mathrm{CO}_{2}$ radiative forcing $\left(\varepsilon=\lambda_{\mathrm{CO} 2} / \lambda_{\mathrm{OHU}}\right)$. By definition, the OHU efficacy (shown as contours in Fig. 1a) has similar spatial structure to the sensitivity map, except that the former is nondimensional. Compositing the $q$ flux for each latitude band (not shown) results in a factor of 3-4 times as large an efficacy for the high-latitude $q$ flux as for the tropics, a result in agreement with that from the aquaplanet in Rose et al. (2014). However, as to be revealed later by the kernel diagnosis, the relative importance of the feedback processes responsible for the larger efficacy of high-latitude $q$ flux can be different from the idealized aquaplanet model and between the two hemispheres.

To delve into the SAT sensitivity across latitudes to the latitudinal location of the $q$ flux, we bundle together the $q$-flux patches from the same latitudinal band $\left(\phi_{k}\right)$ by treating them as if they were driving one experiment forced with the summation of the $q$ fluxes along that latitude, and the corresponding bundled zonal-mean SAT response is simply the summation of the response in these cases. Figure 2 a shows the bundled SAT response normalized by the bundled $q$ flux (thus of unit $\mathrm{K} \mathrm{PW}^{-1}$, ordinate) as a function of the location of the forcing latitude (abscissa), delineating the local and nonlocal effects of the forcing perturbations at each latitude. First, it is remarkable to note that no matter where the $q$ flux is from, it always tends to create a polaramplified warming in SAT, especially in the Northern 

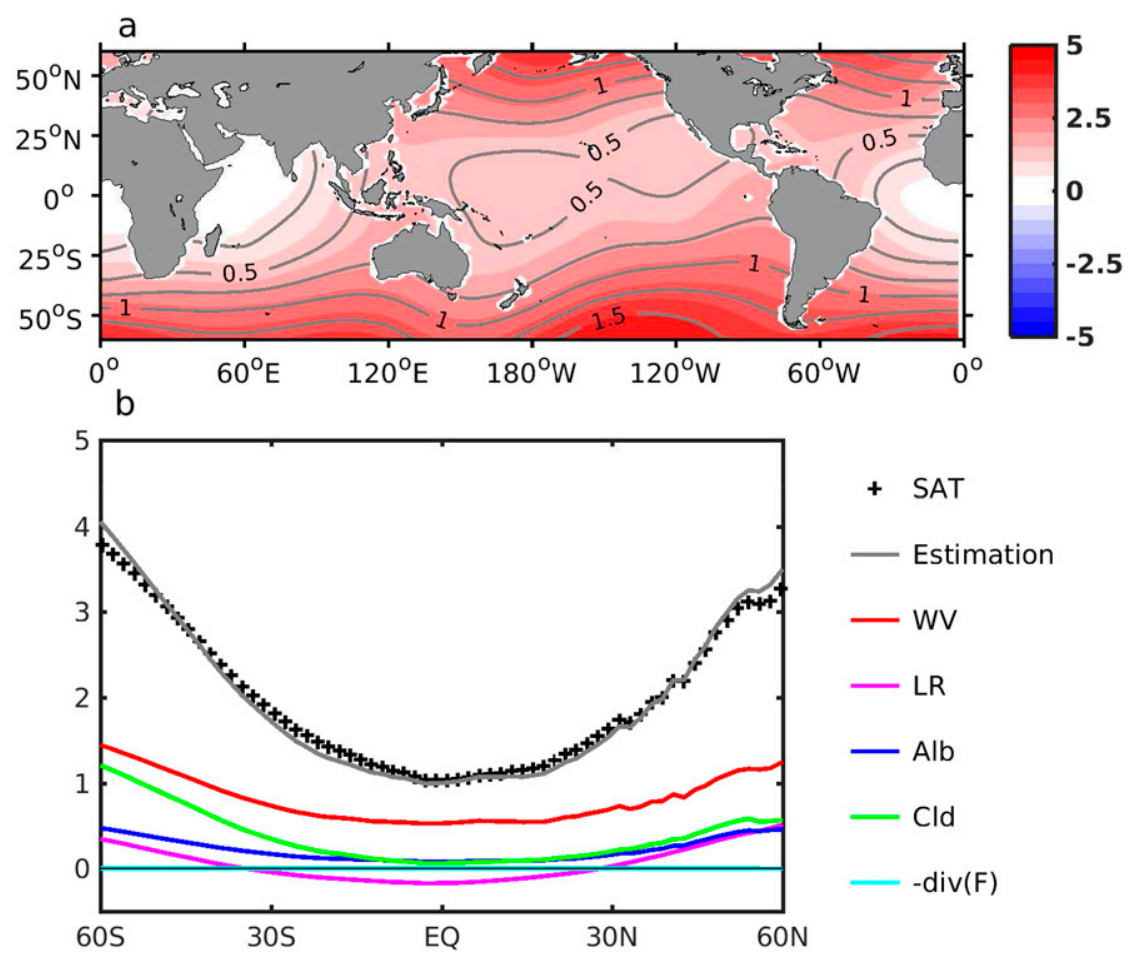

FIG. 1. (a) Global mean SAT sensitivity (shading; $\mathrm{K} \mathrm{PW}^{-1}$ ) and OHU efficacy (contours). A spatial smoother derived from the inpainting algorithm (Garcia 2010) is employed here and in the following figures to ensure that only the statistically robust features are retained. (b) Global mean SAT sensitivity averaged over each latitude (cross) and its replication via Eq. (4) (gray), and the decomposition of the SAT sensitivity into the contribution from WV (red), LR (magenta), Alb (blue), and Cld (green) feedbacks, and AHT convergence [-div $(F)$, cyan].

Hemisphere. More specifically, a $q$ flux applied in the Southern Ocean can induce an accentuated warming not only near the southern pole but also the northern pole. The processes behind the polar-amplified surface warming will be examined next through radiative kernel analysis. Another interesting feature to note is that forcing at high latitude $\left(55^{\circ} \mathrm{S}\right.$ and $\left.57^{\circ} \mathrm{N}\right)$ can produce even more equatorial SAT warming than that produced by the local forcing (centered around equator). Similar results were also noticed in aquaplanet AGCMs (Kang and Xie 2014; Rose et al. 2014; Kang et al. 2017) and this feature has been attributed to the distinct feedbacks to the tropical versus high-latitude forcing sources: A tropical $q$-flux heating leads to a maximum warming in the upper troposphere (hence near the emission level) because of the quasi-moist adiabatic adjustment in the tropics, whereas the warming induced by a high-latitude forcing is trapped near the surface due to the strong atmospheric stability in the polar region. Therefore, the surface warming is more effectively damped by radiation in the tropics than in the high latitudes. The greater warming altruism of the tropics than the high latitudes, to be elaborated in section $3 \mathrm{c}$, is another contributing factor to this feature. Kang and Xie (2014) further identified a strong modulating effect of water vapor and cloud-radiative feedbacks on this warming efficiency contrast between tropical and high-latitude forcings.

To more directly compare with the result of Kang et al. (2017), who investigated the sensitivity of the air temperature to the latitude of the forcing, we plot the zonal-mean air temperature response for all the 11 forcing bands in Fig. 3. Despite using a full physics model in our investigation, the sensitivity of the zonal-mean air temperature to the location of the $q$-flux latitude here resembles remarkably that from an aquaplanet model in Kang et al. (2017, see the left column of their Fig. 4), with a preferred warming in the tropical upper troposphere and a bottom-heavy warming in the high latitudes. Likely, the mechanism identified in Kang et al. (2017), that is, the combination of atmospheric dynamics and air-sea coupling, is also operating here in shaping the common air temperature pattern emerging from the $q$-flux Green's function experiments. The warming in the northern pole here is more bottom confined; it is possibly the result of the shallower inversion layer when sea ice is present. The amplitude of the response here is overall weaker by 
(a) TS

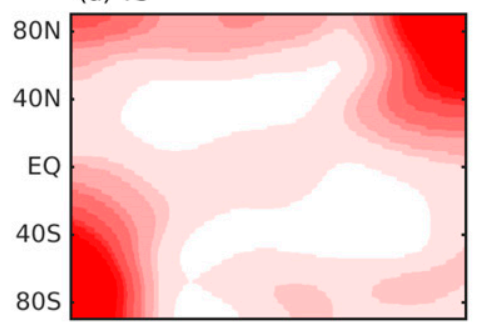

(c) Water vapor

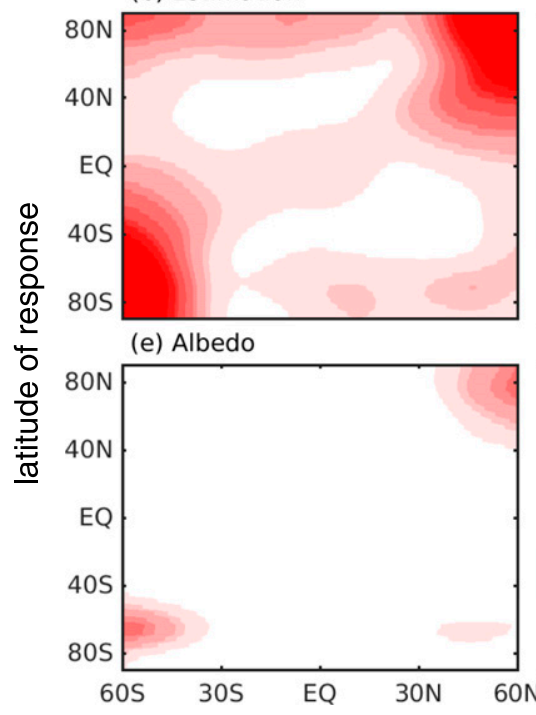

(c) Water vapor

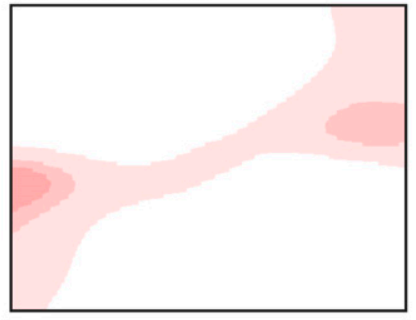

(f) Cloud

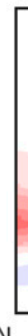

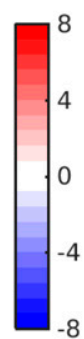

(d) Lapse-rate

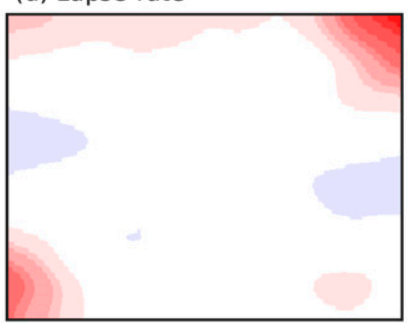

(g) - divF

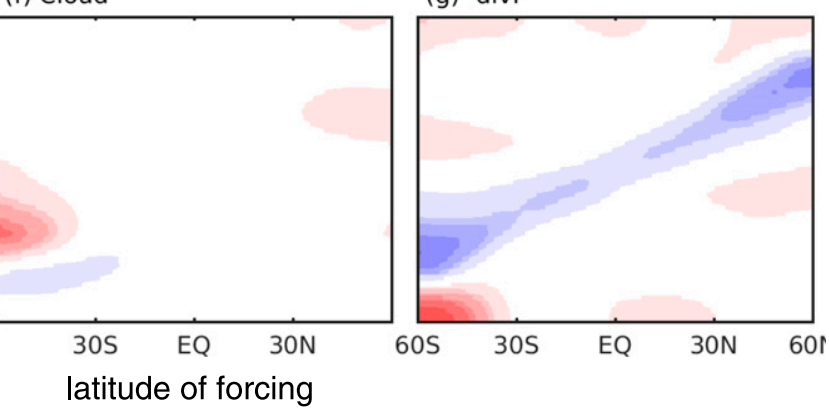

(h)

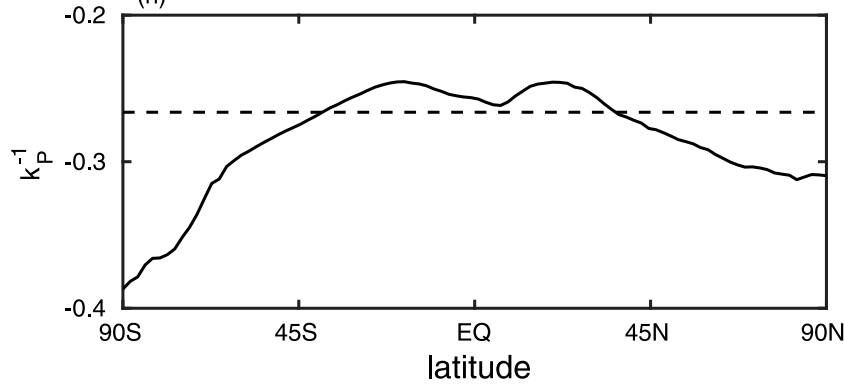

FIG. 2. (a) Zonal-mean SAT sensitivity $\left(\mathrm{K} \mathrm{PW}^{-1}\right)$ to $q$-flux perturbation at different latitudes. (b) Replication of the zonal-mean SAT sensitivity via Eq. (4). (c)-(g) Decomposition of the SAT sensitivity into WV, LR, Alb, and Cld feedbacks, and AHT convergence. (h) Zonal-mean column Planck feedback parameter $k_{P}^{-1}$ with the global averaged value shown as the dashed line.

about a factor of 2 , when the response in both studies is normalized to be the change per PW, in spite of the fact that more positive feedback processes (e.g., ice albedo) are considered, and the land component is included in our full model. However, more systematic examination with a hierarchy of modeling framework will be necessary to find out the actual cause for this magnitude difference.

\section{b. Radiative feedback to SAT}

As explained in section 2, the SAT response, as well as its meridional distribution, can be interpreted as the sum of the effects of radiative feedbacks, AHT convergence, and the $q$ flux, all acting through the Planck column damping. By design, the SAT response can be reproduced via the decomposition shown in Eq. (4) (Figs. 1b, $2 b)$. The global mean SAT attribution to radiative feedbacks, together with the AHT convergence, is displayed in Fig. 1b to elucidate their sensitivity to the location of the $q$ flux ( $x$ axis). One can see that all the feedback fluxes increase with the latitude of the forcing, that is, high-latitude $q$ flux tends to excite greater positive flux from various feedback processes. While the 


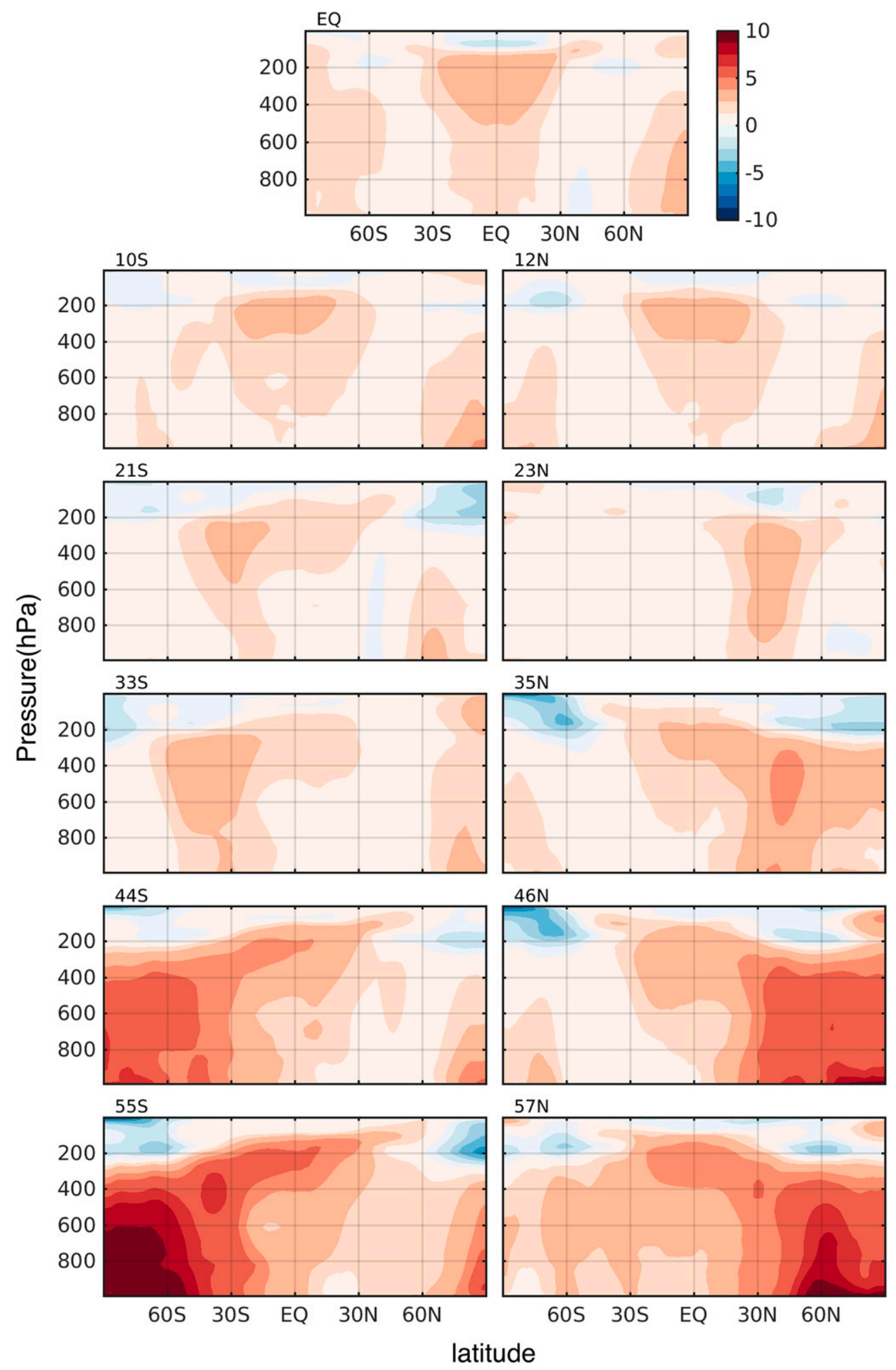

FIG. 3. Zonal-mean atmospheric temperature response $\left(\mathrm{K} \mathrm{PW}^{-1}\right)$ to $q$-flux perturbation at different latitudes. 
(a) SW Cloud Feedback

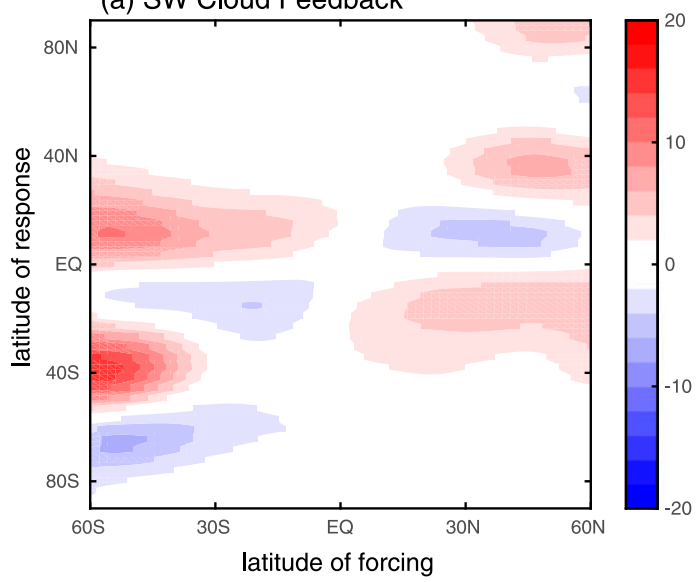

(b) LW Cloud Feedback

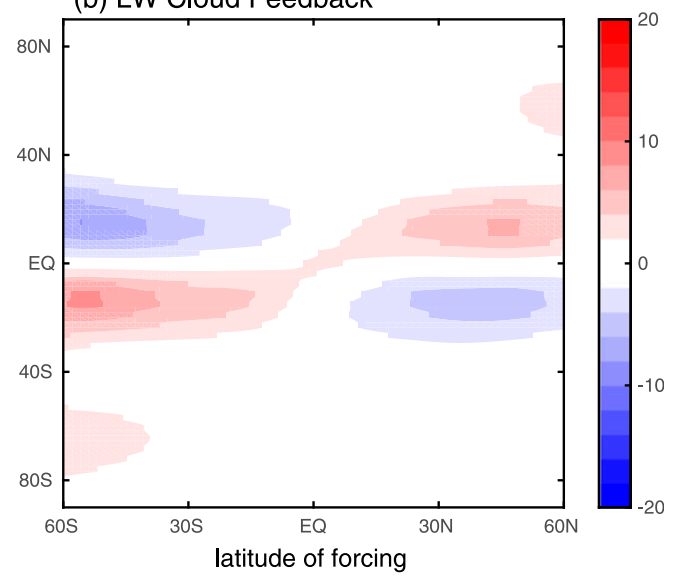

FIG. 4. The estimated zonal-mean sensitivity of (a) SW cloud feedback and (b) LW cloud feedback. Unit is $\mathrm{W} \mathrm{m}{ }^{-2} \mathrm{PW}^{-1}$.

water vapor feedback (red) plays the largest role in amplifying the global mean warming, the cloud feedback (green) exhibits the greatest sensitivity to the latitudinal location of the forcing. The Planck feedback is the major negative feedback, working to counter the positive sum of other feedbacks and the positive $q$-flux forcing (not shown).

Further decomposition of the zonal-mean SAT structures in Fig. $2 \mathrm{a}$ into the contributions from different feedback processes is delineated in Figs. 2c-g. The positive lapse rate feedback at high latitudes is the result of the near-surface temperature inversion (Manabe and Wetherald 1975; Feldl and Roe 2013; Pithan and Mauritsen 2014), and thus is more readily excited by a higher-latitude forcing. A similar argument may be made for the albedo feedback that can only occur where there is ice and snow in the first place, that is, in high latitudes. For the mid- to high-latitude forcings, water vapor feedback maximizes in the subtropics of the forced hemisphere. Further inspection of the overturning circulation indicates that the accentuated water vapor feedback is the result of the moistening by dynamical ascent there, which itself is part of a vertical motion dipole straddling the equator (Fig. 5a) - a salient feature of the intertropical convergence zone (ITCZ) shift toward the heated hemisphere. The descending branch in the opposite hemisphere, on the other hand, acts to desiccate the atmosphere there and prevents the effect of the water vapor feedback from spreading into the opposite hemisphere.

The cloud feedback plays as important a role as others in enhancing the global SAT warming in response to high-latitude forcing as found in earlier studies with both idealized aquaplanet model and full AGCM (e.g., Rose et al. 2014; Kang and Xie 2014; Rugenstein et al. 2016).
The positive cloud radiative feedback in the transitional latitudes between subtropics and midlatitude, more obvious in the Southern Hemisphere, arises predominantly from the SW component (see Fig. 4). Further inspection of the cloud fraction suggests the SW cloud feedback near $40^{\circ} \mathrm{S}$ is the result of the weakened storminess and suppressed cloudiness at that latitude range, inferred from the reduction of the sea level pressure variance (Fig. 5b). Farther south (poleward of $55^{\circ} \mathrm{S}$ ), the $\mathrm{SW}$ cloud radiative cooling dominates the LW warming (Fig. 4); this appears to be the result of the increased high cloud near the southern pole and the enhanced cloud albedo owing to a phase change from ice to liquid (not shown). The latter mechanism has been previously suggested for the negative cloud feedback in the extratropics and high latitudes (Kay et al. 2014; McCoy et al. 2016; Ceppi and Hartmann 2015).

As far as the polar amplification feature of the SAT sensitivity is concerned, AHT (Fig. 2g) can be as important as the lapse rate and albedo feedbacks (Figs. 2d,e). Since the convergence of AHT must be integrated to zero globally, the $-\nabla \cdot F^{\prime}$ term contributes negligibly to the global mean SAT sensitivity as evidenced by the cyan line in Fig. 1b. For each $q$-flux case, however, the divergence of AHT compensates the $q$-flux input locally by delivering heat out of the energy input region to higher latitudes in the native hemisphere and to the opposite hemisphere, hence a diagonal structure results in Fig. 2g. It is particularly notable that AHT under the southern high-latitude $q$-flux forcing appears to contribute to the warming near both poles, more so than the albedo feedback, although admittedly it is not clear to what extent AHT operates independently from the radiative feedbacks. Further experiments with these feedback processes disabled would be needed to truly 
(a) OMEGA 500hPa

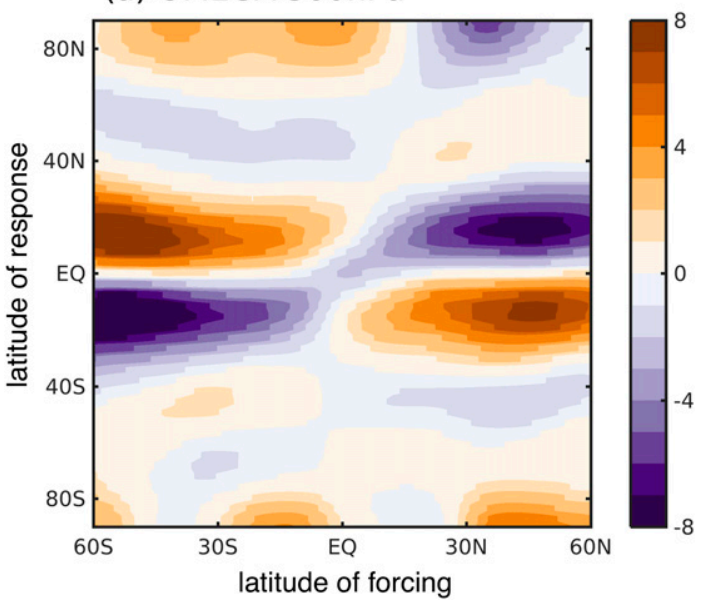

(b) PSL Variance

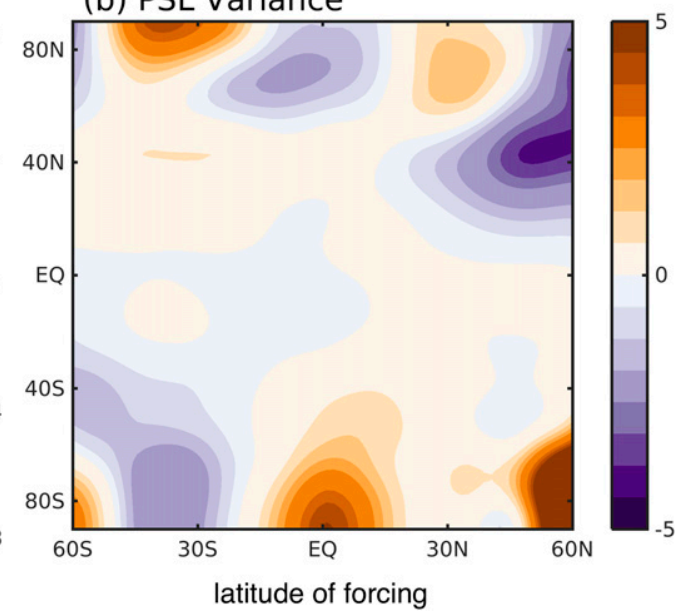

FIG. 5. Zonal-mean sensitivity of (a) $500 \mathrm{mb}$-omega $\left(\mathrm{hPa} \mathrm{day}^{-1} \mathrm{PW}^{-1}\right)$ and (b) sea level pressure variance $\left(\mathrm{hPa}^{2} \mathrm{PW}^{-1}\right)$.

isolate the role of the AHT in the polar-amplified response. Because of the contrast between its negative feedback in the tropics and positive feedback in the mid- to high latitudes, the lapse rate feedback is the leading factor in shaping the polar-amplified warming pattern (Fig. 2d), consistent with the assessment of the polar-amplified SAT response to greenhouse gas forcing by Pithan and Mauritsen (2014). The water vapor feedback, on the other hand, contributes negatively to the polar amplification because of its subtropical accentuation.

The latitudinal structure of $k_{P}^{-1}$ is shown in Fig. $2 \mathrm{~h}$, which is characterized by a poleward enhancement as well, consistent with what one might expect from the Planck feedback: To damp a given TOA forcing anomaly, an air column with lower background mean temperature must warm more. Since all feedbacks, as well as the forcing and AHT convergence, must work through the column Planck feedback parameter to impact on the SAT, the aforementioned polar amplifying effects must have been reinforced by this spatial dependence of the Planck feedback.

The radiative kernel diagnosis elucidates that all of the radiative feedbacks but the Planck feedback warm the forced hemisphere more than the unforced hemisphere. Since the ITCZ always shifts toward the heated hemisphere (Peterson et al. 2000; Chiang and Bitz 2005; Broccoli et al. 2006), these feedbacks should all serve as positive feedbacks to amplify ITCZ shift initiated by the $q$-flux forcing. The relationship between the ITCZ shift and the radiative feedback processes revealed in our $q$-flux Green's function experiments will be examined in future work.

\section{c. Warming altruism of the tropics}

To elucidate the warming altruism of the $q$ flux from different latitudes, we first define the local SAT warming as the areal integral of the SAT response over the area of the local $q$-flux prescription and the remote SAT warming as that over the area elsewhere. Figure 6a illustrates the local and remote warming (curves) as a function of the $q$-flux forcing latitude, as well as their fractional counterparts (colored bars) with respect to the local warming (the fractional local warming becomes unity, as shown by the pink bars). The remote warming is further decomposed into the part in the native hemisphere and that in the opposite hemisphere. Both the local warming and the remote warming in the native hemisphere increase with the latitude of forcing, while the remote warming in the opposite hemisphere exhibits an opposite relationship in general, with a weak nonmonotonicity, to the latitude of forcing. The greater sensitivity of both the local and remote warming (in the native hemisphere and total) to the $q$ flux in higher latitudes compared to lower latitudes can be well explained by the enhanced lapse rate, albedo, and cloud feedbacks (Figs. 6b,c, the black dashed line and its decomposition). One interesting exception is the water vapor feedback, which works to amplify the local warming more in the lower latitudes than the higher latitudes. Viewed through the Murphy-Koop relation (Murphy and Koop 2005) for LW water vapor feedback, $\left[\left(\partial R_{\mathrm{wv}} / \partial \ln q\right)=\left(\partial R_{\mathrm{wv}} / \partial T\right)\left(R_{v} T^{2} / L_{v}\right)\right]$, this result implies that the $T^{2}$ and $\partial R_{\mathrm{wv}} / \partial T$ factors, both being larger in the lower latitudes [see, e.g., Ramanathan and Inamdar (2006) for the latitudinal dependence of the 
(a)

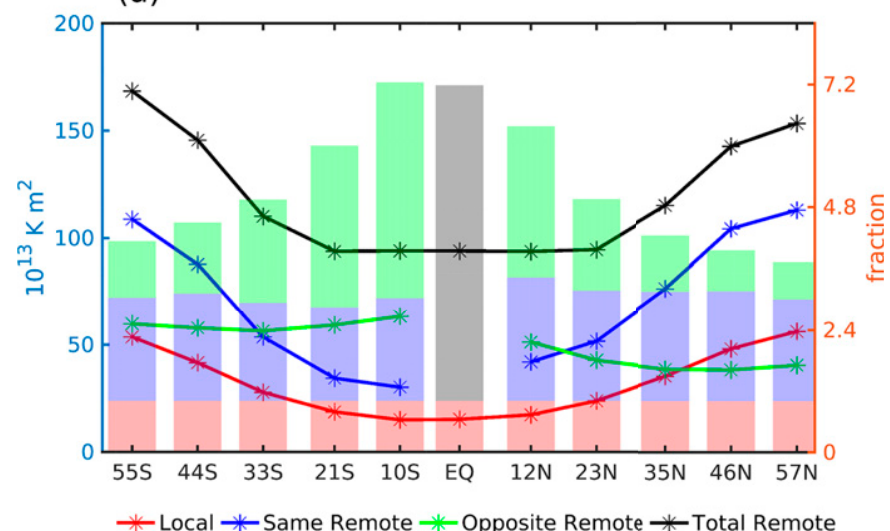

(b) Local

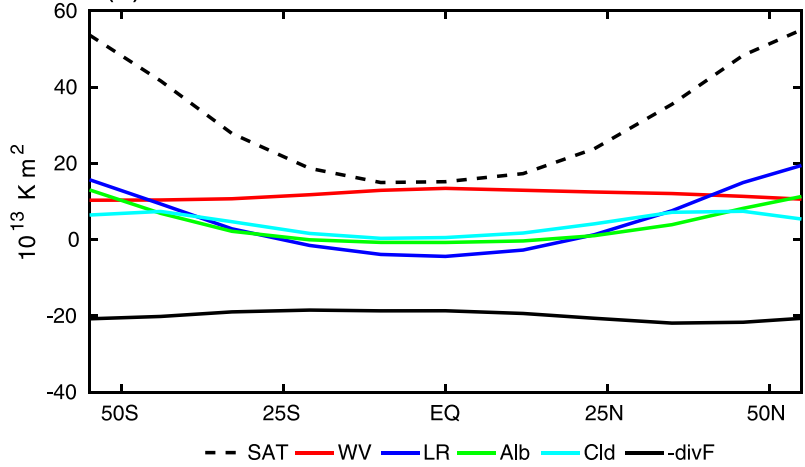

(d) Same Remote

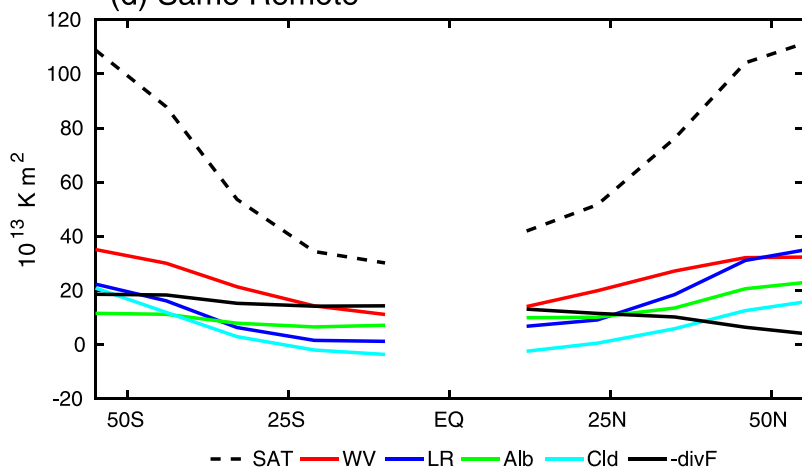

(c) Total Remote

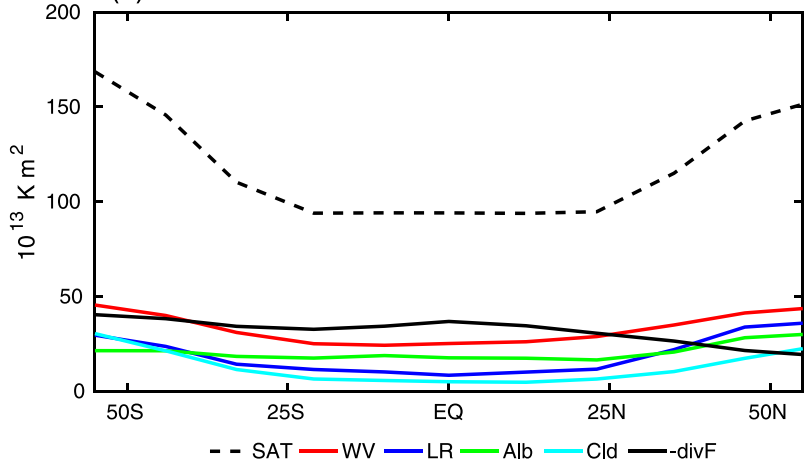

(e) Opposite Remote

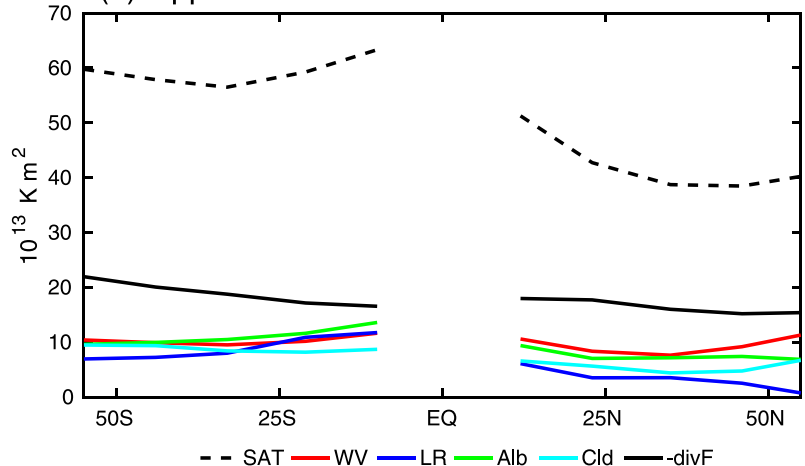

FIG. 6. (a) Area-integrated SAT responses in local region (i.e., region of the $q$ flux, red), total remote region (black line), remote region in the native hemisphere (blue), and remote region in the opposite hemisphere (green). Bars are the fractional responses normalized by the local SAT responses. For the equatorial case, only the local and total remote SAT responses can be defined. (b) Attribution of the areaintegrated SAT response of the local region, (c) total remote region, (d) remote region in the native hemisphere, and (e) remote region in the opposite hemisphere to different feedback effects and AHT convergence.

latter factor], win over the factor of the greater highlatitude local warming $(\delta T)$ under unit local $q$-flux perturbation. Further, an interhemispheric asymmetry exists between the opposite remote warming component forced by $\mathrm{NH} q$ fluxes and that by $\mathrm{SH} q$ fluxes, likely the result of more landmass in the $\mathrm{NH}$ relative to the SH that, everything else being equal, should lead to more SAT warming in the NH because of the small land heat capacity. This argument may also explain the larger native hemispheric warming in the $\mathrm{NH}$ relative to the SH (Figs. 5b,d). The greater cross-equatorial energy transport in response to SH high-latitude forcing (cf. its $\mathrm{NH}$ counterpart) may also have a role to play (black line, Fig. 6e) in this asymmetry.

Defining "altruism" as the ratio of remote warming to local warming, we find that the tropical latitudes exhibit a much greater altruism in sharing the warmth with remote areas. For instance, for one unit of local 
(a) Global Sensitivity

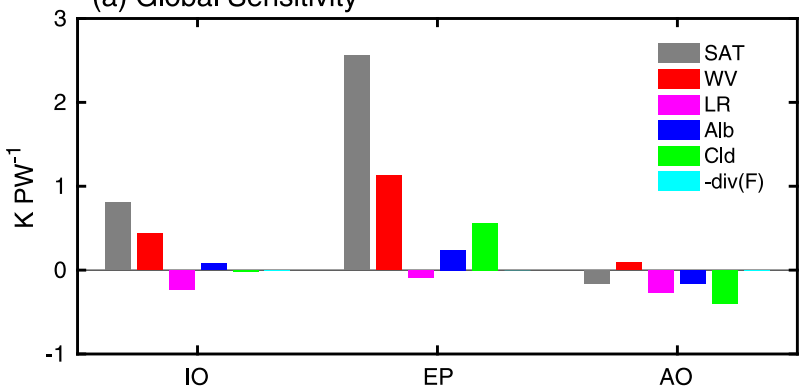

(b) Local Sensitivity

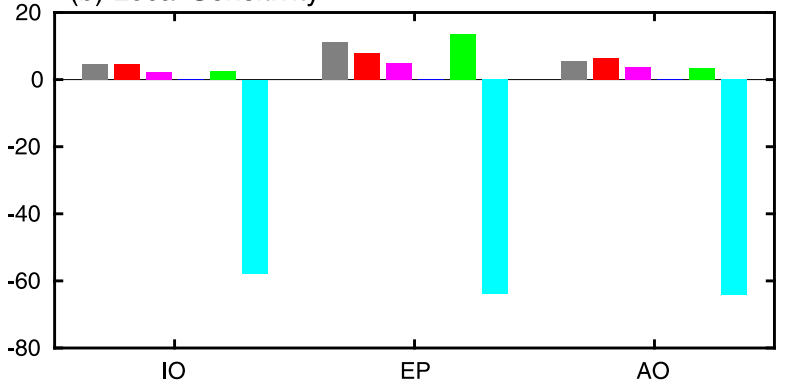

FIG. 7. (a) Global mean SAT sensitivity $\left(\mathrm{K} \mathrm{PW}^{-1}\right)$ to $q$-flux perturbation at IO (mean of $\left[0^{\circ}, 60^{\circ} \mathrm{E}\right]$ and $\left[0^{\circ}, 90^{\circ} \mathrm{E}\right]$ patches), EP (mean of $\left[0^{\circ}, 120^{\circ} \mathrm{W}\right]$ and $\left[0^{\circ}, 90^{\circ} \mathrm{W}\right]$ patches), and $\mathrm{AO}$ (mean of $\left[0^{\circ}, 0^{\circ}\right]$ and $\left[0^{\circ}, 30^{\circ} \mathrm{W}\right]$ patches). (b) As in (a), but for the local SAT sensitivity. Unit is $\mathrm{KPW}^{-1}$.

SAT warming at the equator, the remote warming is 6 times as large (see the gray bar in Fig. 6a). The remote proportion decreases monotonically with the forcing latitudes, down to 3 and 2.5 for the cases of the highest latitude in $\mathrm{SH}\left(55^{\circ} \mathrm{S}\right)$ and $\mathrm{NH}\left(57^{\circ} \mathrm{N}\right)$, respectively. The altruism of the tropics in sharing the warmth has been found in aquaplanet models as well (Rose et al. 2014; Kang and Xie 2014; Kang et al. 2017) and attributed to the different heat transport efficiencies between the tropical Hadley cell system and the midlatitude eddies. In addition, the warming in response to a tropical forcing in the $\mathrm{SH}$ has a greater propensity to spread to the other hemisphere than the other way around. For instance, the $q$ flux at $21^{\circ}$ and $10^{\circ} \mathrm{S}$ can produce more remote warming in the Northern Hemisphere than the total Southern Hemisphere warming. This may be due to interhemispheric asymmetry in the Hadley circulation transporting atmospheric energy northward across the equator in a climatological mean sense.

\section{Zonal asymmetry in the global warming sensitivity}

The investigation above has mainly focused on the meridional contrast of the zonal-mean SAT sensitivity to the $q$ flux from different latitude bands. Another interesting feature shown in Fig. 1a is the zonal asymmetry in the tropics, that is, the same amount of $q$-flux heating in the Pacific basin is able to cause much larger global warming than the same amount of heating applied in the Indian Ocean or the Atlantic Ocean (see also Fig. 7a), and more intriguingly, heating applied in the Atlantic Ocean can even lead to a global cooling. This intriguing zonal asymmetry has received relatively little attention because previous studies usually employed zonally symmetric $q$-flux forcing. Barsugli et al. (2006) mentioned a similar feature in a global warming sensitivity map to prescribed SST (instead of $q$ flux) in a much older version of the community AGCM, yet little was discussed therein about the underlying mechanisms. We are then motivated to look into the three representative regions-eastern equatorial Pacific (EP) with the largest global mean SAT sensitivity, equatorial Indian Ocean (IO) with moderate sensitivity, and equatorial Atlantic Ocean (AO) with negative sensitivity-and to seek for a mechanistic explanation for this zonal asymmetry in the tropics.

As has been done with the zonal-mean SAT sensitivity, we first employ the kernel-based decomposition for the SAT forced by the $q$ flux from these three regions. From a local feedback perspective, all the radiative feedbacks apart from the albedo feedback, which is zero in the tropics, are positive and work together to maintain the local warming in the tropics (Fig. 7b). These local warming feedbacks are much weaker for the IO and AO cases and thus limiting the warming of the local SAT compared to the EP case. However, the amount of energy transported out of the three regions are all similar, implicative of the greater propensity of the IO and AO compared to EP in terms of sharing energy with remote regions. Remotely, in terms of global feedback, the magnitude of the global SAT warming is dictated by water vapor and cloud feedbacks (Fig. 7a), with the greater positive feedbacks leading to greater global SAT warming (cf. EP and IO) and negative feedbacks to global cooling for the AO case. The albedo feedback only plays a secondary role in the global mean SAT response in all three cases.

The exact spatial distribution of these feedbacks is delineated in Fig. 8 for each of the three cases. It is interesting to note a general negative correlation between the feedback patterns of EP and AO for a reason to be elaborated next. For the EP case, the warming pattern is composed of equatorial components associated with water vapor feedback, off-equatorial components attributable mostly to cloud feedback, and the polaramplified components arising mostly from the albedo and lapse rate feedbacks. The positive cloud feedback is dominated by SW flux (not shown) and mostly concentrated over the eastern Indian and Pacific basins, where 

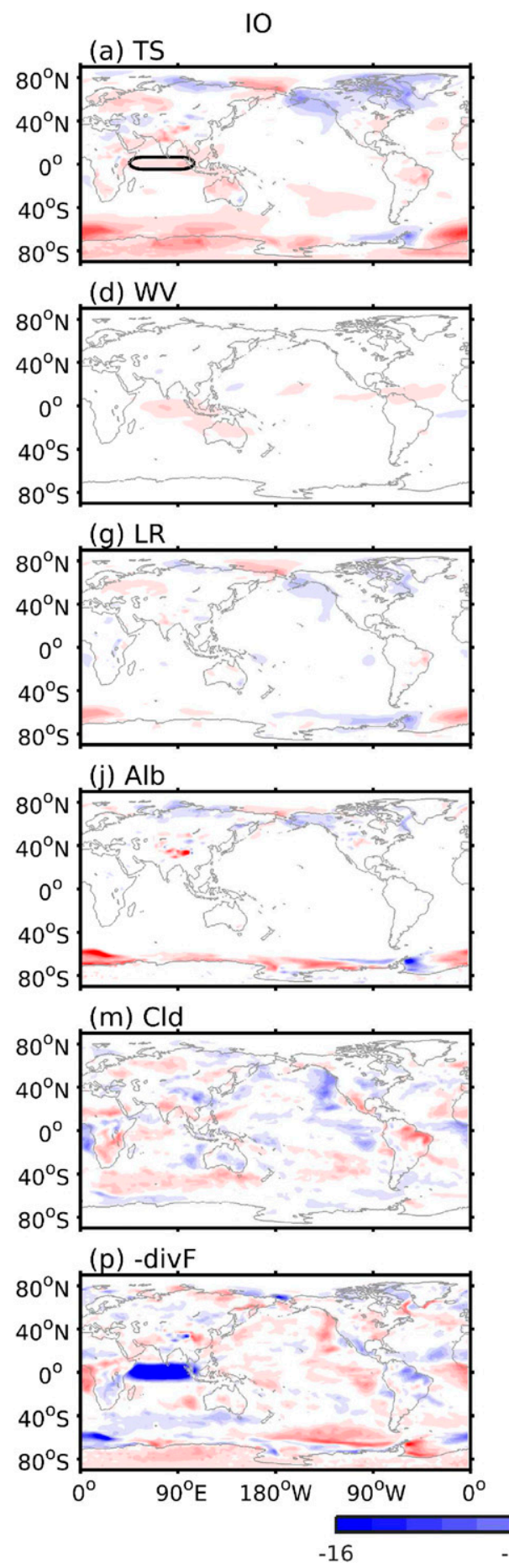
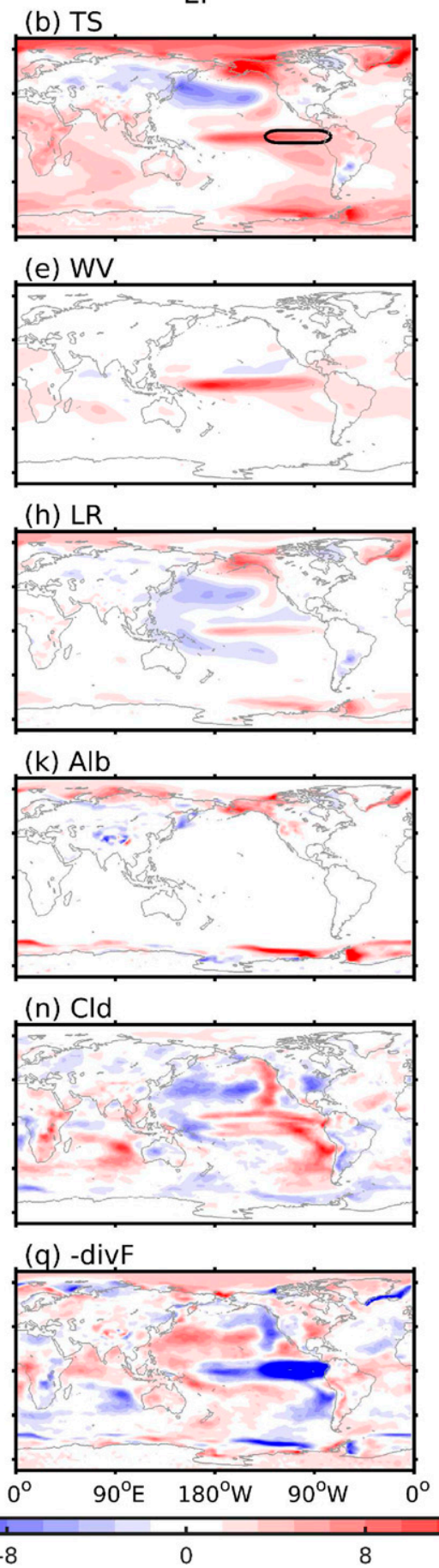
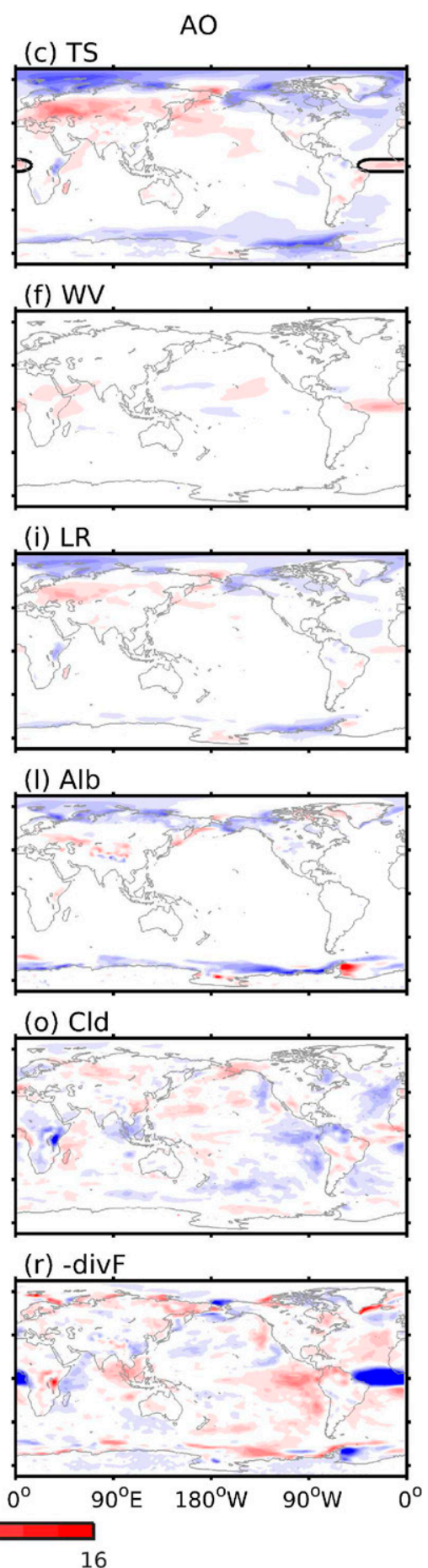

FIG. 8. Global SAT sensitivity $\left(\mathrm{K} \mathrm{PW}^{-1}\right)$ to $q$-flux perturbation at the (a),(d),(g),(j),(m),(p) IO; (b),(e),(h),(k),(n),(q) EP; and (c),(f),(i),(l),(o),(r) AO regions, and their corresponding decomposition into WV, LR, Alb, and Cld feedbacks, and AHT convergence.

the stratocumulus is most prevalent in the climatological distribution. The IO case shows little warming in the tropics, but is characterized by an overall interhemispheric asymmetry with all feedbacks except water vapor contributing to the asymmetry.

\section{SAT sensitivity through the lens of neutral vectors}

Perhaps the most notable feature in Fig. 8 is the IPOlike pattern in the Pacific basin and a polar-amplified 
(a) NV1

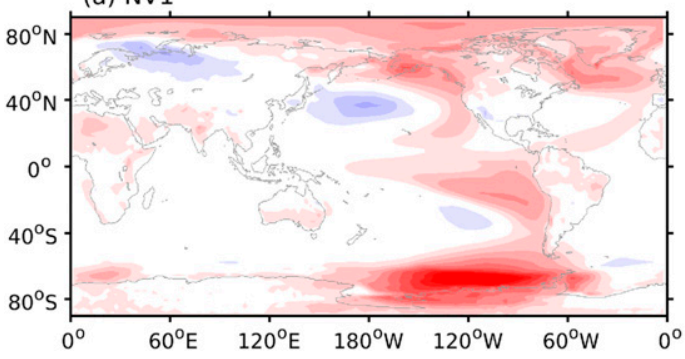

(b) NV2

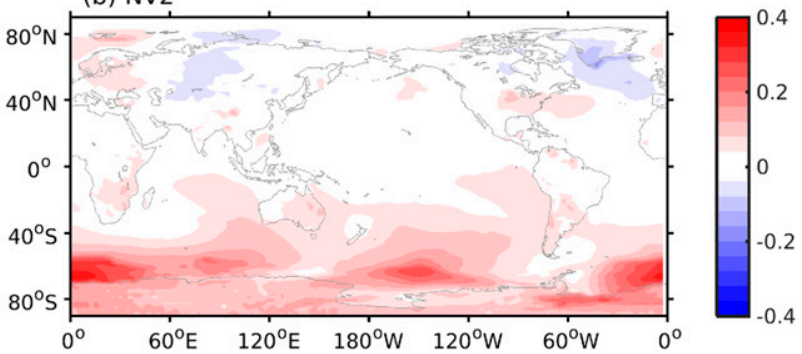

FIG. 9. SAT patterns associated with the leading two neutral vectors derived in Part I.

warming in both hemispheres in response to the EP forcing. The IPO-like pattern was identified in Part I as the leading neutral mode, or the most excitable mode, of the SST linear response function to ocean $q$-flux forcing. The corresponding SAT signature can be easily derived by first projecting the 900-yr-long control time series of SST onto the leading neutral vector to get the corresponding time series and then regressing the $900-\mathrm{yr}$ SAT back onto the resultant time series. This can be done for all the leading 62 neutral modes and the resultant SAT patterns can be utilized to interpret the forced SAT response to the different $q$-flux forcings. For convenience, we will refer to these SAT patterns simply as "SAT neutral modes."

The first two SAT neutral modes are displayed in Fig. 9. It is worth noting that the two leading neutral modes here can be identified with the first two most predictable SAT modes extracted from average predictability time analysis in Srivastava and DelSole (2017, cf. Figs. 9a,b to their Figs. $1 \mathrm{~b}$ and $2 \mathrm{~b}$, respectively). The resemblance between the EP forced pattern and the first neutral mode pattern is evident. In particular, the first neutral vector can explain $57 \%$ of the variance of the forced SAT (Fig. 10b). Like the EP case, AO also projects sharply on the first neutral mode, but negatively, with $32 \%$ of the total variance explained (Fig. 10c). This explains the negative global SAT response to AO and the apparent opposite feedback patterns between these AO and EP cases in Fig. 8. The optimal $q$-flux forcing pattern of the first neutral mode was derived in Part I as the first left singular vector of the linear response function, and it exhibits a positive value in the eastern equatorial Pacific and a negative one in the equatorial Atlantic, having already revealed the possible opposite projections by the EP and AO forcings. Perhaps the most intriguing coincidence is the resemblance of the first neutral mode pattern to that of the global warming surge minus global warming hiatus (cf. Fig. 1b of Liu et al. 2016), offering a new angle for interpreting the hiatus: The hiatus is associated with the most excitable intrinsic mode that can arise from either external forcing or internal variability (due to the internal noise in the climate system), and work to organize global radiative feedbacks optimally for the impact on global SAT.

Different from the above two cases, the IO case projects strongly onto the second neutral mode (explaining (a) $10(54 \%)$

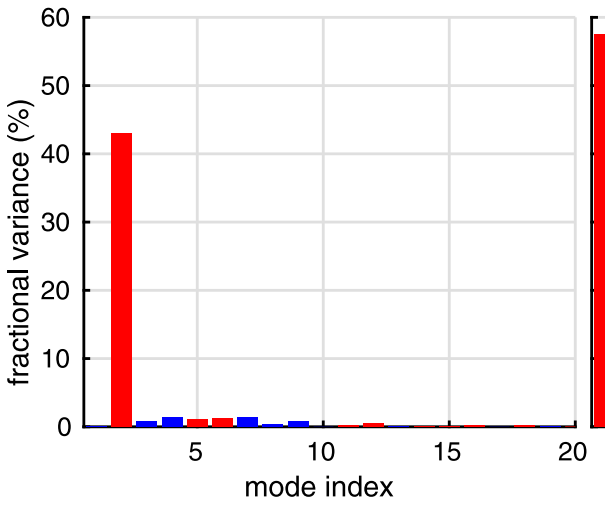

(b) $\operatorname{EP}(77 \%)$

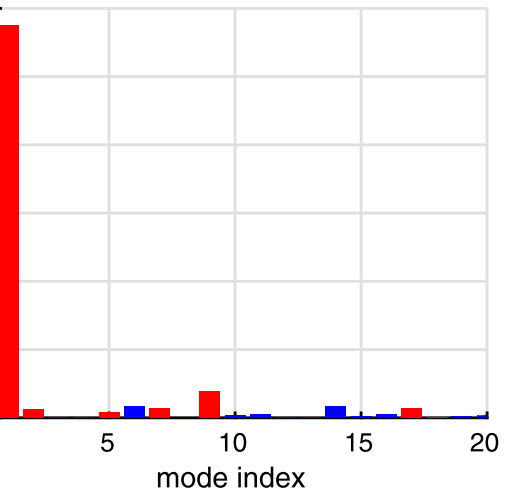

(c) $\mathrm{AO}(60 \%)$

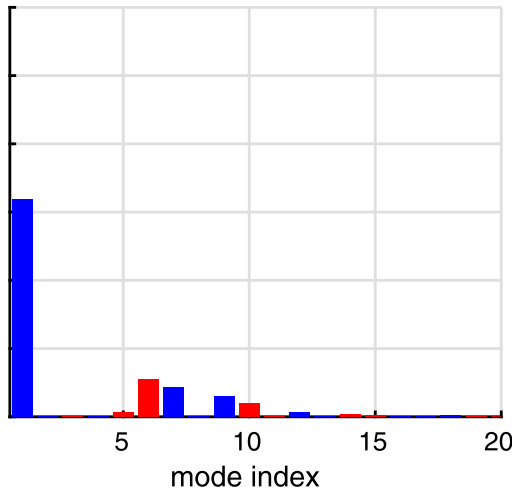

FIG. 10. Fractional variance (\%) of SAT response explained by the leading neutral vectors for the (a) IO, (b) EP, and (c) AO cases. Red (blue) color denotes the contribution to global warming (cooling). Note that only the first 20 neutral vectors are shown. Numbers shown at the top of each panel represent the total variance explained by the leading 62 neutral vectors. 


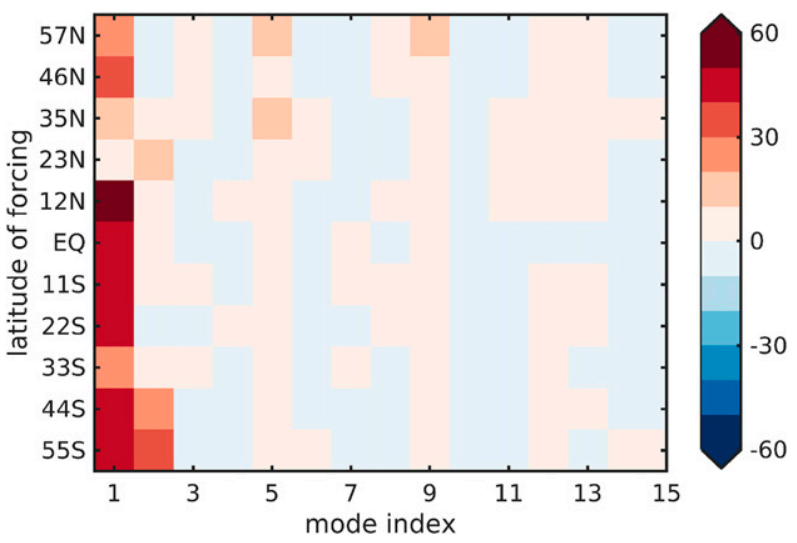

FIG. 11. Fractional variance (\%) of global SAT response explained by the first 15 leading neutral vectors forced by $q$-flux perturbations at different latitudes. The sign convention is that positive (negative) denotes a positive (negative) contribution to net globally integrated warming from the projected mode.

$43 \%$ of total variance; Fig. 10a) that features an interhemispherically asymmetric pattern (Fig. 9b). Because of its hemispherical cancellation and muted anomalies in the tropics, the second neutral mode contributes much less to the global mean SAT warming than the first mode, and thus global SAT merely has a moderate sensitivity to the IO forcing. Despite the recurrence of this pattern from different analysis methods and different data sources, its organizing mechanism has yet to be understood, a topic beyond the scope of the present investigation.

The significance and relevance of the leading neutral modes may be better exemplified in the projection on these modes from the SAT response to the $q$ flux from each forcing latitude. The variance explained by the projections on the first 15 modes for the 11 forcing bands are displayed in Fig. 11, showing a marked concentration of variance explained by the first two modes. The most notable feature is that almost every forcing band can excite a large first neutral mode response, with an intriguing exception of forcing from $23^{\circ} \mathrm{N}$, which appears to be more effective in exciting the second neutral mode. Given the general interhemispheric symmetry of the first neutral mode pattern, the large projections on this mode from the higher latitude forcings in either hemisphere are somewhat unexpected. This nevertheless vindicates the meaning of the neutral mode- the most excitable intrinsic pattern irrespective of the source of the forcing. It is worth noting that higher modes seem to be needed to capture the response to higher-latitude forcings in the $\mathrm{NH}$, likely the result of the greater zonal asymmetry in the $\mathrm{NH}$ compared to the SH. On the other hand, the high-latitude forcings in the $\mathrm{NH}$ and $\mathrm{SH}$ tend to project oppositely onto the second neutral mode as expected from the interhemispheric asymmetry in its spatial pattern (Fig. 9b).
The effectiveness of each of the $q$-flux patches in exciting the first and second SAT neutral modes is elucidated in Fig. 12 as the fractional variance the neutral mode can explain for each response, with the negative sign indicating negative projection and negative global warming. It echoes the results of Figs. 8 and 10: Eastern equatorial Pacific forcing can most effectively excite the first neutral mode, western equatorial IO forcing the second neutral mode, and equatorial $\mathrm{AO}$ forcing the negative first neutral mode. Interestingly, $q$ fluxes in the Southern Ocean are effective in driving both the first and second neutral modes, underpinning the importance of the Southern Ocean heat uptake in mediating the Southern Hemispheric and even the global temperature response to external climate perturbations.

\section{Conclusions}

A comprehensive set of slab AGCM experiments forced by $q$ flux from an array of rectangular areas covering the global open ocean are conducted to evaluate the SAT response sensitivity to the ocean heat forcing from each representative location of the global ocean. The results verify the earlier finding in an idealized aquaplanet that global-mean SAT response is much more sensitive to $q$-flux perturbation in high-latitude oceans than in tropical oceans, with the corresponding OHU efficacy being a factor of 3-4 times as large in the high latitudes as that in the tropical oceans. Comparing to the aquaplanet results, some interesting interhemispheric asymmetry emerges with regard to the TOA radiative feedback mechanisms for the amplified SAT sensitivity to high-latitude $q$-flux forcing. While the cloud radiative feedback plays the leading role in amplifying the global SAT response to $\mathrm{SH}$ high-latitude forcing, as in the aquaplanet models, the contribution from the combination of the albedo and lapse rate feedbacks can exceed the cloud effect for the case of the $\mathrm{NH}$ high-latitude forcing. Thus, the presence of the sea ice and large landmass as in the $\mathrm{NH}$ can make a difference compared to the aquaplanet in terms of the relative importance of the respective radiative feedbacks. Although the importance of cloud radiative feedback in the large efficacy of high-latitude oceanic $q$ flux has become a recurrent notion, the reasons behind it appear to be complicated, involving possible cancellation between the shortwave and longwave effects and coupling with the atmospheric dynamics.

Inspecting the meridional structures of the zonalmean SAT response to the $q$ flux from each latitude band reveals an intrinsic nature of Earth's climate: It always warms more near the poles than the lower 

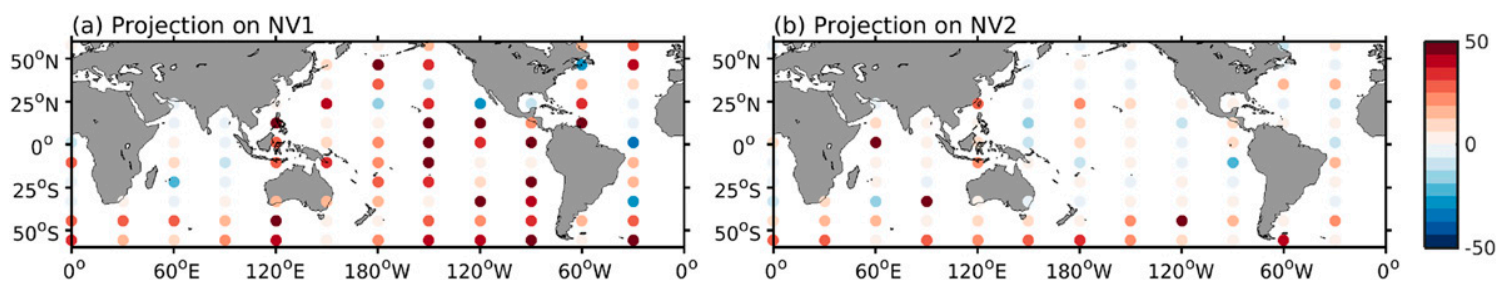

FIG. 12. Fractional variance (\%) of global SAT response explained by the (a) first and the (b) second neutral vectors forced by $q$-flux perturbations at different locations. The sign convention is that positive (negative) denotes a positive (negative) contribution to net globally integrated warming from the projected mode.

latitudes no matter where the oceanic heat forcing comes from. Making use of the inverse of the column Planck feedback operator, we can additively decompose the zonal-mean SAT response into the parts due to the feedbacks of 1) water vapor, 2) cloud, 3) albedo, 4) lapse rate, and 5) AHT convergence. It is found that the latter three feedbacks all play a part in the polar amplification of the SAT response, with the lapse rate feedback making the largest contribution. Most remarkably, the AHT also works in the same direction as these feedbacks in producing the polar-amplified SAT response. This hints at a possibility that the AHT alone can work independently of these feedbacks to induce a polaramplified SAT warming. Evidence does exist to support the notion that the diffusive nature of the poleward AHT down the poleward gradient of the mean moist static energy can afford a polar-amplified surface response in the absence of the aforementioned positive feedbacks (e.g., Alexeev et al. 2005; Roe et al. 2015). But atmospheric dynamics and the radiative feedback processes are inextricably coupled in a full AGCM, preventing a clean isolation of the role of the atmospheric dynamics.

The $q$-flux Green's function experiments also allow us to probe into the issue of warming altruism, that is, the propensity to share the warmth with other latitudes when a latitudinal band is heated locally by the ocean. Consistent with earlier studies (Kang and Xie 2014; Rose et al. 2014), the equatorial atmosphere exhibits the greatest altruism of sharing the warmth with higher latitudes, while the altruism decreases monotonically as the forcing region progresses to higher latitudes. The larger altruism of the tropics might reflect the distinct efficiency of transporting heat between the Hadley circulation and midlatitude eddies (Walker and Schneider 2006; Kang et al. 2009). Additionally, the warming altruism also manifests an intriguing interhemispheric asymmetry: Under the same amount of $q$-flux forcing from the ocean below, a SH atmosphere column (at $x^{\circ} \mathrm{S}$ ) tends to share more warming with the $\mathrm{NH}$ than a $\mathrm{NH}$ column at the opposite latitude $\left(x^{\circ} \mathrm{N}\right)$. The greater landmass and the associated relatively small heat capacity in the $\mathrm{NH}$ are likely among the reasons for this asymmetry. Nevertheless, the greater SH-to-NH AHT at the equator may implicate the vigorous stationary wave in the $\mathrm{NH}$ as a more effective means in transporting heat poleward than the more zonally symmetric circulation regime of the $\mathrm{SH}$.

Furthermore, our Green's function approach allows the revelation of the zonal heterogeneity of the OHU efficacy. Despite the overall low efficacy of the tropical oceans, the $\mathrm{IO}$ and the $\mathrm{AO}$ are the areas where the ocean heat flux is the least effective in driving global surface warming, a result not dissimilar from the SST patch experiments in Barsugli et al. (2006). It is intriguing that some isolated $q$-flux patches in the tropical oceans even produce a cooling in the global mean SAT. This zonal heterogeneity can be interpreted through the leading neutral modes of SAT rendered from the singular value decomposition of the linear response function derived in Part I. The response to the heat flux from EP can project strongly and positively onto the leading neutral mode that organizes global feedbacks conspiringly for both the relatively large mean warming and the polar amplification of the warming, whereas heat flux from $\mathrm{AO}$ excites a negative phase of the leading neutral mode and hence global cooling. The IO flux, on the other hand, excites the second neutral mode characteristic of interhemispherically asymmetric patterns and thus moderate global mean warming.

The neutral modes offer a new perspective to look at the global climate feedback by injecting the element of dynamics perspective. Note the simple fact that if there were no circulation in the atmosphere, warming in one location would not be communicated efficiently to another. At least in this CESM1.1-SOM climate system, the global warming hiatuses and surges can be understood through the organizing effect of the first neutral mode, while the large OHU efficacy of the Southern Ocean may be understood as the large sensitivity of the first two neutral modes to the $q$ flux from the Southern Ocean. The dynamical origins of these leading neutral modes remain to be understood through further careful observational and modeling studies. 
Acknowledgments. This study was supported by the U.S. Department of Energy Office of Science Biological and Environmental Research (BER) as part of the Regional and Global Climate Modeling program. PNNL is operated for DOE by Battelle Memorial Institute under contract DE-AC05-75RL01830. FL was supported by the China Scholarship Council. YH is supported by the Discovery Program of the Natural Sciences and Engineering Council of Canada (RGPIN 418305-13). YL is supported by National Science Foundation of China (41676002 and 41376009). All the model data output has been archived on NERSC High Performance Storage System (HPSS) and can be accessed upon request to the correspondence author.

\section{REFERENCES}

Alexeev, V. A., P. L. Langen, and J. R. Bates, 2005: Polar amplification of surface warming on an aquaplanet in "ghost forcing" experiments without sea ice feedbacks. Climate Dyn., 24, 655-666, https://doi.org/10.1007/s00382-005-0018-3.

Armour, K. C., C. M. Bitz, and G. H. Roe, 2013: Time-varying climate sensitivity from regional feedbacks. J. Climate, 26, 4518-4534, https://doi.org/10.1175/JCLI-D-12-00544.1.

Barsugli, J. J., and P. D. Sardeshmukh, 2002: Global atmospheric sensitivity to tropical SST anomalies throughout the Indo-Pacific basin. J. Climate, 15, 3427-3442, https://doi.org/ 10.1175/1520-0442(2002)015<3427:GASTTS>2.0.CO;2.

— S.-I. Shin, and P. D. Sardeshmukh, 2006: Sensitivity of global warming to the pattern of tropical ocean warming. Climate Dyn., 27, 483-492, https://doi.org/10.1007/s00382-006-0143-7.

Broccoli, A. J., K. A. Dahl, and R. J. Stouffer, 2006: Response of the ITCZ to Northern Hemisphere cooling. Geophys. Res. Lett., 33, L01702, https://doi.org/10.1029/2005GL024546.

Ceppi, P., and D. L. Hartmann, 2015: Connections between clouds, radiation, and midlatitude dynamics: A review. Curr. Climate Change Rep., 1, 94-102, https://doi.org/10.1007/s40641-015-0010-x.

Chang, P., and Coauthors, 2008: Oceanic link between abrupt changes in the North Atlantic Ocean and the African monsoon. Nat. Geosci., 1, 444-448, https://doi.org/10.1038/ngeo218.

Chiang, J. C. H., and C. M. Bitz, 2005: Influence of high latitude ice cover on the marine intertropical convergence zone. Climate Dyn., 25, 477-496, https://doi.org/10.1007/s00382-005-0040-5.

Crook, J. A., P. M. Forster, and N. Stuber, 2011: Spatial patterns of modeled climate feedback and contributions to temperature response and polar amplification. J. Climate, 24, 3575-3592, https://doi.org/10.1175/2011JCLI3863.1.

Dee, D. P., and Coauthors, 2011: The ERA-Interim reanalysis: Configuration and performance of the data assimilation system. Quart. J. Roy. Meteor. Soc., 137, 553-597, https://doi.org/ 10.1002/qj.828.

Delworth, T., S. Manabe, and R. J. Stouffer, 1993: Interdecadal variations of the thermohaline circulation in a coupled oceanatmosphere model. J. Climate, 6, 1993-2011, https://doi.org/ 10.1175/1520-0442(1993)006<1993:IVOTTC $>2.0$. CO;2.

Feldl, N., and G. H. Roe, 2013: Four perspectives on climate feedbacks. Geophys. Res. Lett., 40, 4007-4011, https://doi.org/ 10.1002/grl.50711.

Forster, P. M. de F., M. Blackburn, R. Glover, and K. P. Shine, 2000: An examination of climate sensitivity for idealised climate change experiments in an intermediate general circulation model. Climate Dyn., 16, 833-849, https://doi.org/10.1007/ s003820000083.

Garcia, D., 2010: Robust smoothing of gridded data in one and higher dimensions with missing values. Comput. Stat. Data Anal., 54, 1167-1178, https://doi.org/10.1016/j.csda.2009.09.020.

Garuba, O. A., and B. A. Klinger, 2016: Ocean heat uptake and interbasin transport of the passive and redistributive components of surface heating. J. Climate, 29, 7507-7527, https:// doi.org/10.1175/JCLI-D-16-0138.1.

, J. Lu, F. Liu, and H. A. Singh, 2018: The active role of the ocean in the temporal evolution of climate sensitivity. Geophys. Res. Lett., 45, 306-315, https://doi.org/10.1002/2017GL075633.

Geoffroy, O., D. Saint-Martin, D. J. L. Olivié, A. Voldoire, G. Bellon, and S. Tytéca, 2013: Transient climate response in a two-layer energy-balance model. Part I: Analytical solution and parameter calibration using CMIP5 AOGCM experiments. J. Climate, 26, 1841-1857, https://doi.org/10.1175/JCLI-D-12-00195.1.

Gregory, J. M., and T. Andrews, 2016: Variation in climate sensitivity and feedback parameters during the historical period. Geophys. Res. Lett., 43, 3911-3920, https://doi.org/10.1002/ 2016 GL068406.

Hansen, J., M. Sato, and R. Reudy, 1997: Radiative forcing and climate response.J. Geophys. Res., 102, 6831-6864, https:// doi.org/10.1029/96JD03436.

Huang, Y., Y. Xia, and X. Tan, 2017: On the pattern of $\mathrm{CO}_{2}$ radiative forcing and poleward energy transport. J. Geophys. Res. Atmos., 122, 10 578-10 593, https://doi.org/10.1002/2017JD027221.

Joshi, M., K. Shine, M. Ponater, N. Stuber, R. Sausen, and L. Li, 2003: A comparison of climate response to different radiative forcings in three general circulation models: Towards an improved metric of climate change. Climate Dyn., 20, 843-854, https://doi.org/10.1007/s00382-003-0305-9.

Kang, S. M., and S.-P. Xie, 2014: Dependence of climate response on meridional structure of external thermal forcing. J. Climate, 27, 5593-5600, https://doi.org/10.1175/JCLI-D-13-00622.1.

— D. M. W. Frierson, and I. M. Held, 2009: The tropical response to extratropical thermal forcing in an idealized GCM: The importance of radiative feedbacks and convective parameterization. J. Atmos. Sci., 66, 2812-2827, https://doi.org/ 10.1175/2009JAS2924.1.

— , K. Park, F.-F. Jin, and M. F. Stuecker, 2017: Common warming pattern emerges irrespective of forcing location. J. Adv. Model. Earth Syst., 9, 2413-2424, https://doi.org/ 10.1002/2017MS001083.

Kay, J. E., B. Medeiros, Y. T. Hwang, A. Gettelman, J. Perket, and M. G. Flanner, 2014: Processes controlling Southern Ocean shortwave climate feedbacks in CESM. Geophys. Res. Lett., 41, 616-622, https://doi.org/10.1002/2013GL058315.

Liu, F., J. Lu, O. Garuba, L. Ruby Leung, Y. Luo, and X. Wan, 2018: The sensitivity of surface temperature to oceanic forcing via q-flux Green's function experiments. Part I: Linear response function. J. Climate, 31, 3625-3641, https://doi.org/ 10.1175/JCLI-D-17-0462.1.

Liu, W., S.-P. Xie, and J. Lu, 2016: Tracking ocean heat uptake during the surface warming hiatus. Nat. Commun., 7, 10926, https://doi.org/10.1038/ncomms10926.

Lu, J., and M. Cai, 2009: A new framework for isolating individual feedback processes in coupled general circulation climate models. Part I: Formulation. Climate Dyn., 32, 873-885, https://doi.org/10.1007/s00382-008-0425-3.

Manabe, S., and R. T. Wetherald, 1975: The effects of doubling the $\mathrm{CO}_{2}$ concentration on the climate of a general circulation 
model. J. Atmos. Sci., 32, 3-15, https://doi.org/10.1175/ 1520-0469(1975)032<0003:TEODTC > 2.0.CO;2.

Marshall, J., J. R. Scott, K. C. Armour, J.-M. Campin, M. Kelley, and A. Romanou, 2015: The ocean's role in the transient response of climate to abrupt greenhouse gas forcing. Climate Dyn., 44, 2287-2299, https://doi.org/10.1007/s00382-014-2308-0.

McCoy, D. T., I. Tan, D. L. Hartmann, M. D. Zelinka, and T. Storelvmo, 2016: On the relationships among cloud cover, mixed-phase partitioning, and planetary albedo in GCMs. J. Adv. Model. Earth Syst., 8, 650-668, https://doi.org/10.1002/ 2015 MS000589.

Mlawer, E. J., S. J. Taubman, P. D. Brown, M. J. Iacono, and S. A. Clough, 1997: Radiative transfer for inhomogeneous atmospheres: RRTM, a validated correlated-k model for the longwave. J. Geophys. Res., 102, 16 663-16 682, https://doi.org/ 10.1029/97JD00237.

Murphy, D. M., and T. Koop, 2005: Review of the vapour pressures of ice and supercooled water for atmospheric applications. Quart. J. Roy. Meteor. Soc., 131, 1539-1565, https://doi.org/ 10.1256/qj.04.94.

Neale, R. B., and Coauthors, 2012: Description of the NCAR Community Atmosphere Model (CAM 5.0). NCAR Tech. Note NCAR/TN-486+STR, 274 pp., www.cesm.ucar.edu/ models/cesm1.0/cam/docs/description/cam5_desc.pdf.

Peterson, L. C., G. H. Haug, K. A. Hughen, and U. Röhl, 2000: Rapid changes in the hydrologic cycle of the tropical Atlantic during the last glacial. Science, 290, 1947-1951, https://doi.org/ 10.1126/science.290.5498.1947.

Pithan, F., and T. Mauritsen, 2014: Arctic amplification dominated by temperature feedbacks in contemporary climate models. Nat. Geosci., 7, 181-184, https://doi.org/10.1038/ngeo2071.

Ramanathan, V., and A. Inamdar, 2006: The radiative forcing due to clouds and water vapor. Frontiers of Climate Modeling, J. T. Kiehl and V. Ramanathan, Eds., Cambridge University Press, 119-151.

Read, J. F., and W. J. Gould, 1992: Cooling and freshening of the subpolar North Atlantic Ocean since the 1960s. Nature, 360, 55-57, https://doi.org/10.1038/360055a0.

Roe, G. H., N. Feldl, K. C. Armour, Y.-T. Hwang, and D. M. W. Frierson, 2015: The remote impacts of climate feedbacks on regional climate predictability. Nat. Geosci., 8, 135-139, https://doi.org/10.1038/ngeo2346.
Rose, B. E. J., and L. Rayborn, 2016: The effects of ocean heat uptake on transient climate sensitivity. Curr. Climate Change Rep., 2, 190-201, https://doi.org/10.1007/s40641-016-0048-4.

$\longrightarrow$, K. C. Armour, D. S. Battisti, N. Feldl, and D. D. B. Koll, 2014: The dependence of transient climate sensitivity and radiative feedbacks on the spatial pattern of ocean heat uptake. Geophys. Res. Lett., 41, 1071-1078, https://doi.org/10.1002/2013GL058955.

Rugenstein, M. A. A., K. Caldeira, and R. Knutti, 2016: Dependence of global radiative feedbacks on evolving patterns of surface heat fluxes. Geophys. Res. Lett., 43, 9877-9885, https:// doi.org/10.1002/2016GL070907.

Senior, C. A., and J. F. B. Mitchell, 2000: The time-dependence of climate sensitivity. Geophys. Res. Lett., 27, 2685-2688, https:// doi.org/10.1029/2000GL011373.

Soden, B. J., I. M. Held, R. C. Colman, K. M. Shell, J. T. Kiehl, and C. A. Shields, 2008: Quantifying climate feedbacks using radiative kernels. J. Climate, 21, 3504-3520, https://doi.org/ 11175/2007JCLI2110.1.

Srivastava, A., and T. DelSole, 2017: Decadal predictability without ocean dynamics. Proc. Natl. Acad. Sci. USA, 114, 21772182, https://doi.org/10.1073/pnas.1614085114.

Walker, C. C., and T. Schneider, 2006: Eddy influences on Hadley circulations: Simulations with an idealized GCM. J. Atmos. Sci., 63, 3333-3350, https://doi.org/10.1175/JAS3821.1.

Williams, K. D., W. J. Ingram, and J. M. Gregory, 2008: Time variation of effective climate sensitivity in GCMs. J. Climate, 21, 5076-5090, https://doi.org/10.1175/2008JCLI2371.1.

Winton, M., K. Takahashi, and I. M. Held, 2010: Importance of ocean heat uptake efficacy to transient climate change. J. Climate, 23, 2333-2344, https://doi.org/10.1175/2009JCLI3139.1.

_ , S. M. Griffies, B. L. Samuels, J. L. Sarmiento, and T. L. Frölicher, 2013: Connecting changing ocean circulation with changing climate. J. Climate, 26, 2268-2278, https://doi.org/ 10.1175/JCLI-D-12-00296.1.

Xie, P., and G. K. Vallis, 2012: The passive and active nature of ocean heat uptake in idealized climate change experiments. Climate Dyn., 38, 667-684, https://doi.org/10.1007/s00382-011-1063-8.

Zhao, C., S. A. Klein, S. Xie, X. Liu, J. S. Boyle, and Y. Zhang, 2012: Aerosol first indirect effects on non-precipitating lowlevel liquid cloud properties as simulated by CAM5 at ARM sites. Geophys. Res. Lett., 39, L08806, https://doi.org/10.1029/ 2012GL051213. 